\title{
EVOLUTIONARY TRENDS IN LITHOPHAGIC VERTEBRATES
}

WHITTLE, Christopher, Harvard University Extension School, c/o A.W. Crompton, Museum of Comparative Zoology, 26 Orford Street, Cambridge, MA 02138

All classes of extant vertebrates have lithophagic species. The debate about why animals eat stones has quietly raged for over a century. Except for a documented physiological need in a few Recent bird and fish species, few can agree why they are ingested, but they have figured in scientific literature since the 1600 's. Gastroliths have been used as stratigraphic indicators for geologists. They have been used as clues to biomechanics and feeding behavior for biologists. The presence of gastroliths in primitive archosauromorphs dates to the Jurassic mesosuchia and can be traced to Recent euschia. Gastroliths found in sauropodomorphs and ornithischians have been alleged to indicate higher levels of metabolic processes. Two large groups of sauropterygians, the younginoids and the plesiosaurs are rarely found without a clutch of stones with their skeletons. Gastroliths have been discovered in Permian and Triassic amphibians, Miocene and Recent pinnipeds, and many Recent reptiles. The presence of gastroliths in a fossil specimen is an important indicator of ontogenetic and phylogenetic characteristics that should be considered in tandem with the associated osteological material. 